\title{
Effect of upgrading concrete strength class on fire performance of reinforced concrete columns
}

\author{
T. Gernay, V. Peric, B. Mihaylov \\ University of Liege, Belgium
}

T. Molkens

Sweco, Belgium

J.M. Franssen

University of Liege, Belgium

\begin{abstract}
High strength concrete (HSC) provides several advantages over normal strength concrete (NSC) and is being used in multi-story buildings for reducing the dimensions of the columns sections and increasing the net marketable area. However, upgrading of concrete strength class in a building may affect the fire performance, due to higher rates of strength loss with temperature and higher susceptibility to spalling of HSC compared with NSC. Reduction of columns sections also leads to increased member slenderness and faster temperature increase in the section core. These detrimental effects are well known, but their impact on fire performance of structures has not been established in terms of comparative advantage between NSC and HSC. In other words, it is not clear whether the consideration of fire resistance limits the opportunities for use of HSC for reducing the dimensions of columns sections in multi-story buildings. This research aims to address this question by comparing the fire behaviour of reinforced concrete columns made of NSC and HSC using nonlinear finite element modelling. The evolution of load bearing capacity of the columns is established as a function of the fire exposure duration. A 15-story car park structure is adopted as a case study with alternative designs for the columns based on strength classes ranging from C30 to C90. Results show that, although the replacement of NSC by HSC accelerates the reduction rate of columns capacity under fire, the columns generally have significant reserves in resistance leading to sufficient fire resistance. This study gives an insight into the impact of replacing stocky sections in NSC by more slender sections in HSC on fire resistance rating for multi-story structures.
\end{abstract}

\section{INTRODUCTION}

High strength concrete (HSC) has become a commonly used material over the last decades, in particular in tall buildings where it allows to increase the net marketable area. As it carries loads more efficiently than normal strength concrete (NSC), it is also specified where architectural considerations call for small support elements. The reduction in member size that can be obtained with HSC results in an increase in usable area. Alternatively, for a fixed column size, longer spans can be supported which leads to a reduced number of supports. HSC also provides advantages in terms of durability. These advantages have resulted in the increased use of HSC observed lately in various applications of civil engineering.

An important requirement for building structures is the performance under fire situations. Previous research has shown that HSC behaves differently than NSC at elevated temperature (Phan and Carino, 1998). The most notable differences regard the relative loss of compressive strength with temperature and the occurrence of spalling. For these two aspects, the performance of HSC is lower than that of NSC, i.e. HSC experiences higher rates of strength loss with temperature and a higher susceptibility to spalling. In addition, HSC is often used to reduce the size of structural members. However, this reduction may be detrimental to the fire performance as it leads to faster temperature increase in the section core of the members, and in- 
creased member slenderness which may lead to increased second-order effects. For all these reasons, consideration of fire loading may partly neutralize the advantages of HSC.

The objective of this research is to investigate to what extent the fire performance of structural members is affected when HSC is used instead of NSC. After discussing the various factors that can lead to a shorter fire resistance for a HSC design, compared with a NSC design, a case study is adopted to quantify these effects in a realistic design. The case study consists in a 15-story car park structure designed according to Eurocode. It focuses on the fire resistance of the car park columns. Alternative designs are adopted with concrete strength classes ranging from C30 to C90. The evolution of the load bearing capacity of the columns under standard fire is established by numerical modeling in order to assess the consequence of upgrading the concrete strength class in terms of fire resistance of the car park.

\section{DESCRIPTION OF THE EFFECTS OF UPGRADING CONCRETE STRENGTH CLASS}

\subsection{Effect on the rate of strength loss with temperature}

The reduction of strength with temperature is more severe for HSC than for NSC, particularly in the range of $50-250^{\circ} \mathrm{C}$ (Phan and Carino, 1998; Cheng et al., 2004). In this study, the reduction of compressive strength at elevated temperature is considered according to the values given in Eurocode 1992-1-2 (EC2, 2004b), see Figure 1. For HSC, strength properties are given in three classes in Eurocode, which depend on the characteristic strength of concrete at ambient temperature. The higher the class, the more pronounced the relative reduction in strength is with temperature. As a result, HSC members lose a larger percentage of their capacity at a given temperature, compared to NSC members.

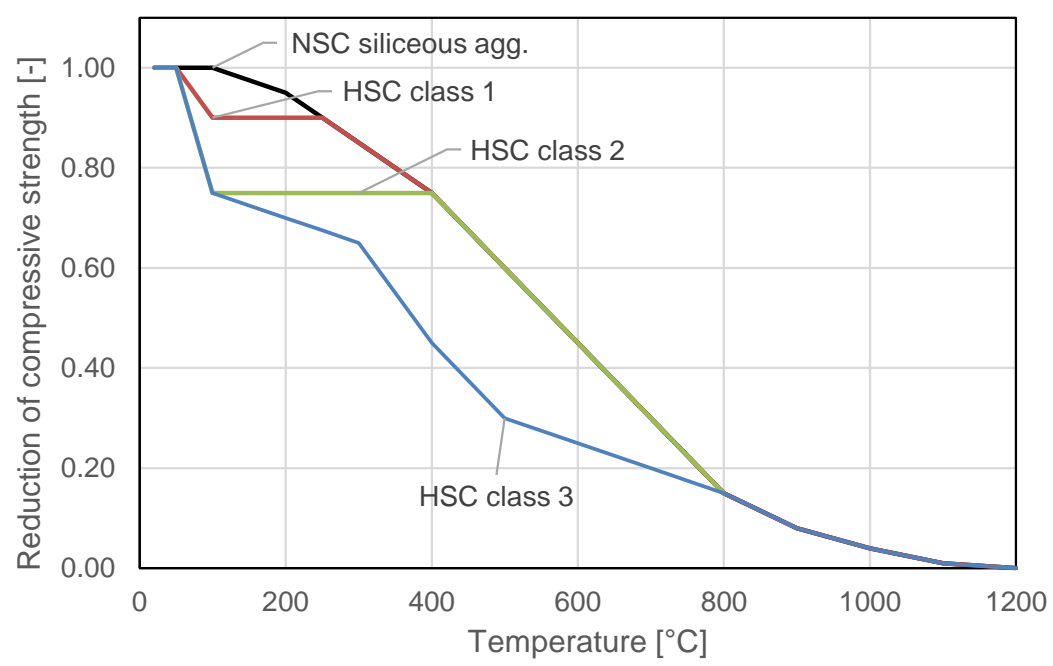

Figure 1. Reduction of concrete compressive strength at elevated temperature (from [4]). Class 1: C55/67, C60/75 - Class 2: C70/85, C80/95 - Class 3: C90/105.

The HSC laws of Figure 1 have been implemented in the nonlinear finite element software SAFIR $^{\circledR}$ (Franssen, 2005; Franssen and Gernay, 2017). This software has been developed at University of Liege for the analysis of building structures in fire. For NSC, siliceous aggregates are assumed in this study. Note that the reduction in strength is more pronounced for NSC with siliceous aggregates than calcareous aggregates; yet even with siliceous aggregates, NSC remains comparatively less affected by temperature than HSC.

\subsection{Effect on the rate of temperature increase in the section core}

The main advantage of HSC over NSC is that it carries the loads more effectively, hence allowing for a reduction of size of the structural members. However, in case of fire exposure, struc- 
tural members with a smaller section get heated faster (as they have a larger massivity factor, or ratio between perimeter and cross section area).

For instance, Figure 2 shows the temperature distribution after 2 hours of fire exposure in a $60 \mathrm{~cm} \times 60 \mathrm{~cm}$ section (left) and in a $40 \mathrm{~cm} \times 40 \mathrm{~cm}$ section (right), computed with SAFIR. Assuming that the $60 \mathrm{~cm} \times 60 \mathrm{~cm}$ section is in NSC with a strength of $40 \mathrm{MPa}$, and the $40 \mathrm{~cm} \times 40$ $\mathrm{cm}$ section is in HSC with a strength of $90 \mathrm{MPa}$, the two have (approximately) the same load bearing capacity at ambient temperature. Yet due to its lower massivity factor, the NSC section takes much longer to heat. After 2 hours of fire, a large part at its core is still below $100^{\circ} \mathrm{C}$. This provides the stocky NSC section a larger inherent fire resistance compared with the more slender HSC section.
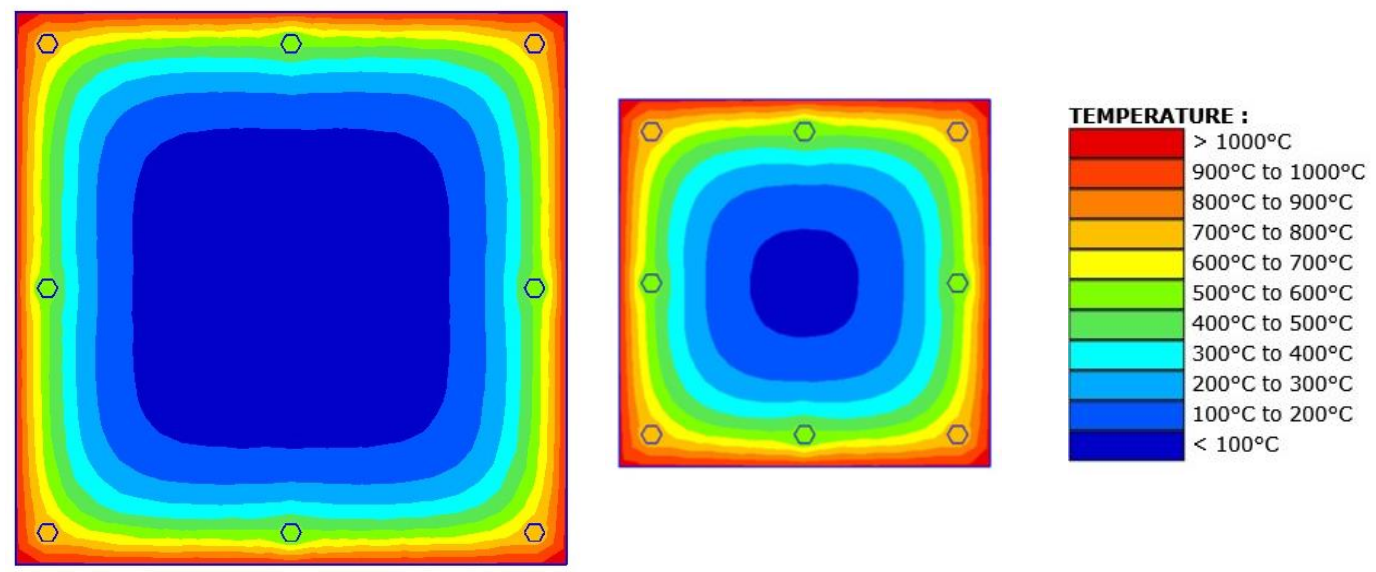

Figure 2. Temperature distribution after 2 hours of standard ISO fire in a $60 \times 60\left(\mathrm{~cm}^{2}\right)$ section (left) and in a $40 \times 40\left(\mathrm{~cm}^{2}\right)$ section (right).

\subsection{Effect on the member slenderness}

The use of higher concrete strength class for reducing the size of the cross sections leads to increased member slenderness (which effect is not sufficiently compensated by the higher Young modulus of HSC). As a result, second-order effects are expected to be more pronounced in slender, HSC design compared with stocky, NSC design. Besides, even if the HSC column slenderness remains moderate at ambient temperature, the role of second-order effects can become significant at elevated temperature because of the stiffness reduction caused by the fire. Bamonte (2008) has shown that second-order effects can play a considerable role in stability of HSC columns in fire.

\subsection{Effect on the risk of spalling}

Another consequence of using HSC in case of fire is the increased propensity to spalling. A large amount of research has shown that HSC structural members are particularly prone to spalling and that this phenomenon can seriously impair their fire resistance (Kodur, 2010).

Spalling is a complex phenomenon, resulting from the combined effect of stresses (mechanical and thermal) and pore pressure. Currently the modeling of the hygro-thermo-mechanical mechanisms leading to spalling in fire-exposed concrete remains a very challenging task. No satisfying model has emerged for predicting the phenomenon of spalling in numerical simulations at the scale of building structural members. Typically in thermo-mechanical finite element software, spalling is not accounted for because the moisture flow and the development of pore pressures during heating are not captured. Meanwhile, extensive research efforts have been conducted on the measures to employ to prevent the apparition of spalling (e.g. Pliya et al., 2011). The Eurocode (EC2, 2004b) gives different methods that should be provided in particular for high strength concrete. Hence, the designer is required to take the appropriate measures when using HSC, e.g. by including in the concrete mix at least $2 \mathrm{~kg} / \mathrm{m}^{3}$ of monofilament polypropylene fibers. Such measures allow mitigating the phenomenon of spalling. Assuming this 
type of measure is adopted in the design in accordance with the codes, and given the complexity of predicting spalling occurrence in numerical simulations, spalling is neglected in this study.

\section{FIRE RESISTANCE OF COLUMNS MADE OF HSC AND NSC}

\subsection{Method}

The effects discussed in Section 2 will influence the behaviour of concrete members in fire. In this section, the fire behaviour of reinforced concrete (RC) columns made of NSC and HSC is analyzed using nonlinear finite element modelling, to compare the fire performance of the different columns. The analyses are conducted with SAFIR.

Four concrete characteristic (cylinder) strengths are taken into account in the analyses: 40 $\mathrm{MPa}$ (NSC), $60 \mathrm{MPa}$ (HSC class 1), $70 \mathrm{MPa}$ (HSC class 2) and $90 \mathrm{MPa}$ (HSC class 3). The studied columns are $2.5 \mathrm{~m}$ high and simply supported at their extremities, with a geometrical imperfection of maximum amplitude equal to $5 \mathrm{~mm}$. The columns have a square cross section and are reinforced with 8 steel bars of $20 \mathrm{~mm}$ diameter. The axis cover is $35 \mathrm{~mm}$. The material models given in Eurocode (EC2, 2004b) are adopted for steel and concrete at elevated temperature, including the compressive strength reduction as a function of the concrete class as plotted in Figure 1. Transient creep strain is considered explicitly in the concrete model (Gernay, 2012; Gernay and Franssen, 2012). The columns are subjected to a vertical load at the top and then to ISO fire on their four sides, the load being kept constant. For a given load, a transient thermomechanical simulation is performed until failure of the column, or up to maximum four hours of fire exposure if the column does not fail within four hours. The simulation is repeated for different load ratios. In the end, the relationship between the applied load ratio and the fire resistance time is obtained for each column. More details are given in (Gernay, 2016).

It is noteworthy that some of the effects discussed in Section 2 are inherent to the HSC material (i.e. the strength loss and spalling), whereas others are a consequence of the reduction in size that is made possible by the use of HSC (i.e. the rate of temperature increase and the slenderness). In order to distinguish between the two types of effects, the comparative analysis between HSC and NSC considers two different configurations, namely: columns with the same load bearing capacity (hence a smaller cross section for the HSC column), and columns with the same cross section.

\subsection{Columns with the same load bearing capacity}

First, columns with approximately the same load bearing capacity are compared. Hence for each concrete strength, the dimension $\mathrm{c}$ of the square cross section is determined as the minimum dimension for which the column load bearing capacity reaches at least $14,500 \mathrm{kN}$, with $\mathrm{c}$ a multiple of $5 \mathrm{~cm}$, see Table 1 . Here, the benefit of using HSC over NSC lies in the fact that, to support a given load, the cross section dimensions of the columns can be reduced. The (unfactored) load bearing capacity of the columns at ambient temperature, $\mathrm{N}_{\mathrm{R}, \mathrm{SAFIR}}$, which is given in Table 1 has been determined with SAFIR. It includes the second order effects. The ratio between $\mathrm{N}_{\mathrm{R}, \mathrm{SAFIR}}$ and the section ultimate capacity, $\mathrm{N}_{\mathrm{u}, \mathrm{k}}$, is also given; it indicates the significance of the second order effects. It can be seen that this ratio decreases with the section size, i.e., columns in higher concrete grade are more susceptible to second order effects. The effect remains limited at ambient temperature, but can be more significant at elevated temperature.

Table 1. Characteristics of the columns for a given load bearing capacity.

\begin{tabular}{ccccccc}
\hline $\begin{array}{c}\text { Concrete } \\
{[-]}\end{array}$ & $\begin{array}{c}\mathrm{f}_{\mathrm{ck}} \\
{[\mathrm{MPa}]}\end{array}$ & $\begin{array}{c}\mathrm{c} \\
{[\mathrm{cm}]}\end{array}$ & $\begin{array}{c}\mathrm{A}_{\mathrm{s}} \\
{\left[\mathrm{cm}^{2}\right]}\end{array}$ & $\begin{array}{c}\mathrm{N}_{\mathrm{R}, \mathrm{SAFIR}} \\
{[\mathrm{kN}]}\end{array}$ & $\begin{array}{c}\mathrm{N}_{\mathrm{R}, S A F I R} / \mathrm{N}_{\mathrm{u}, \mathrm{k}} \\
{[\%]}\end{array}$ & $\begin{array}{c}\mathrm{A} / \mathrm{V} \\
{\left[\mathrm{m}^{-1}\right]}\end{array}$ \\
\hline NSC & 40 & 60 & 25.1 & 15130 & 97.3 & 6.7 \\
HSC 1 & 60 & 50 & 25.1 & 15527 & 96.4 & 8.0 \\
HSC 2 & 70 & 45 & 25.1 & 14617 & 95.8 & 8.9 \\
HSC 3 & 90 & 40 & 25.1 & 14654 & 95.0 & 10.0 \\
\hline
\end{tabular}


Figure 3 shows the evolution of the load bearing capacity as a function of the duration of the standard ISO fire for the columns of Table 1. It is clear that the fire performance degrades with the increase in concrete class. The NSC and the HSC class 3 columns could carry the same load at ambient temperature; however after 90 minutes of ISO fire exposure, the NSC column can still withstand a load of $11,260 \mathrm{kN}$ whereas the HSC class 3 column can only carry $6,990 \mathrm{kN}$.
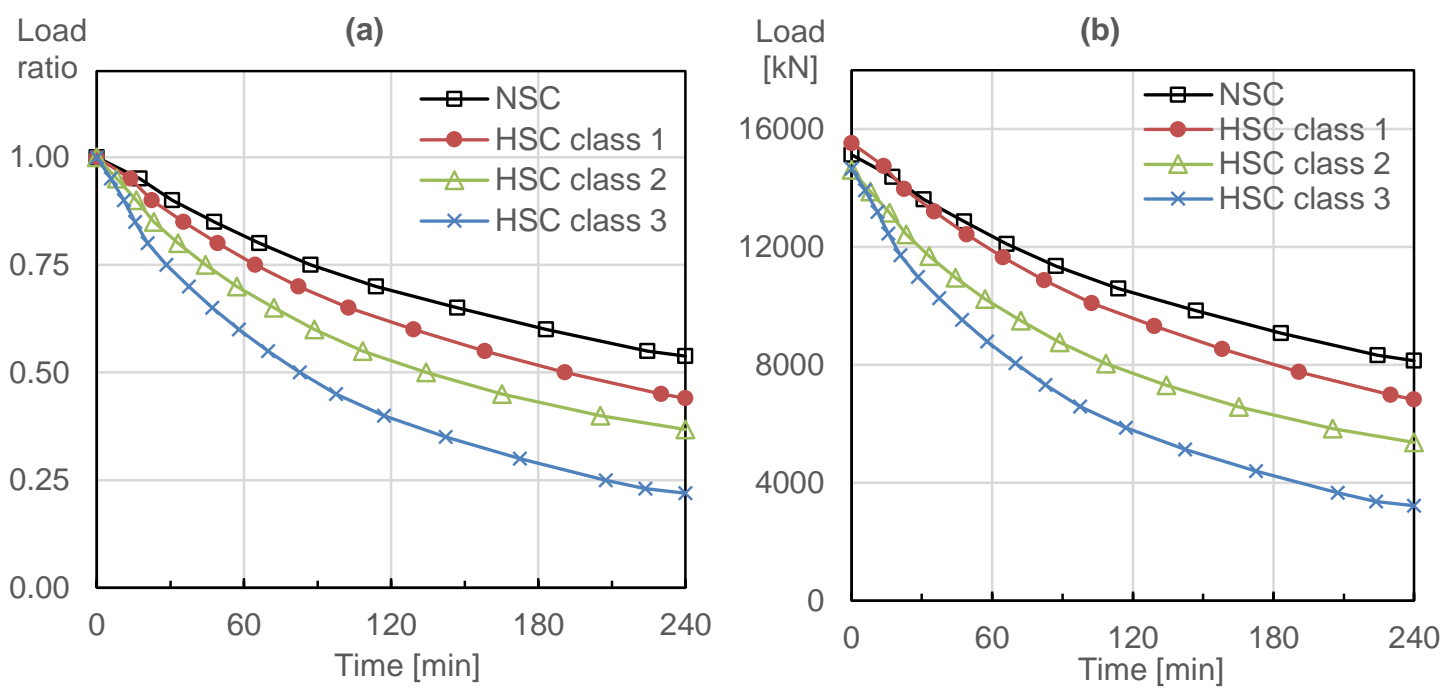

Figure 3. Evolution of load bearing capacity as a function of exposure time to standard ISO fire, in load ratio (a) and in absolute value (b). The columns are designed for a given load bearing capacity.

\subsection{Columns with the same cross section}

Secondly, columns with the same cross section dimensions are analyzed. The columns have a square cross section of $50 \mathrm{~cm}$ side. The load bearing capacity at ambient temperature, obtained by numerical simulation, increases with the concrete strength (Table 2). In this configuration, the section factor and hence the temperature evolution is identical in the HSC and the NSC sections. Also, the second order effects have proportionally the same influence on all columns. In such a case, the use of HSC allows for the column to carry a larger load than if NSC was used; therefore it may be possible, for instance, to increase the spans and reduce the number of columns.

Table 2. Characteristics of the columns for a given cross section.

\begin{tabular}{|c|c|c|c|c|c|c|}
\hline $\begin{array}{c}\text { Concrete } \\
{[-]}\end{array}$ & $\begin{array}{c}\mathrm{f}_{\mathrm{ck}} \\
{[\mathrm{MPa}]}\end{array}$ & $\begin{array}{c}\mathrm{c} \\
{[\mathrm{cm}]}\end{array}$ & $\begin{array}{c}\mathrm{A}_{\mathrm{s}} \\
{\left[\mathrm{cm}^{2}\right]}\end{array}$ & $\begin{array}{c}\mathrm{N}_{\mathrm{R}, \mathrm{SAFIR}} \\
{[\mathrm{kN}]}\end{array}$ & $\begin{array}{c}\mathrm{N}_{\mathrm{R}, \mathrm{SAFIR}} / \mathrm{N}_{\mathrm{u}, \mathrm{k}} \\
{[\%]}\end{array}$ & $\begin{array}{l}\mathrm{A} / \mathrm{V} \\
{\left[\mathrm{m}^{-1}\right]}\end{array}$ \\
\hline NSC & 40 & 50 & 25.1 & 10764 & 96.5 & 8.0 \\
\hline HSC 1 & 60 & 50 & 25.1 & 15527 & 96.4 & 8.0 \\
\hline HSC 2 & 70 & 50 & 25.1 & 17907 & 96.4 & 8.0 \\
\hline HSC 3 & 90 & 50 & 25.1 & 22670 & 96.3 & 8.0 \\
\hline
\end{tabular}

Figure 4 shows the evolution of the load bearing capacity as a function of the duration of the standard ISO fire for the columns of Table 2. Despite the fact that the columns have all the same cross section, there remains a difference in fire performance between concretes of different characteristic strengths. As can be seen in Figure 4a, the column in HSC class 3 exhibits a proportionally more severe reduction in load capacity under fire compared with the columns in NSC and in HSC class 1. The column in HSC class 2 exhibits an intermediate behavior. Overall, the difference between the curves is less pronounced than in the first set of analysis. This was expected, since the factors related to the variation of section size have been eliminated in this second configuration. Here, the different behaviors are only due to the differences in material properties at elevated temperature (Figure 1). 

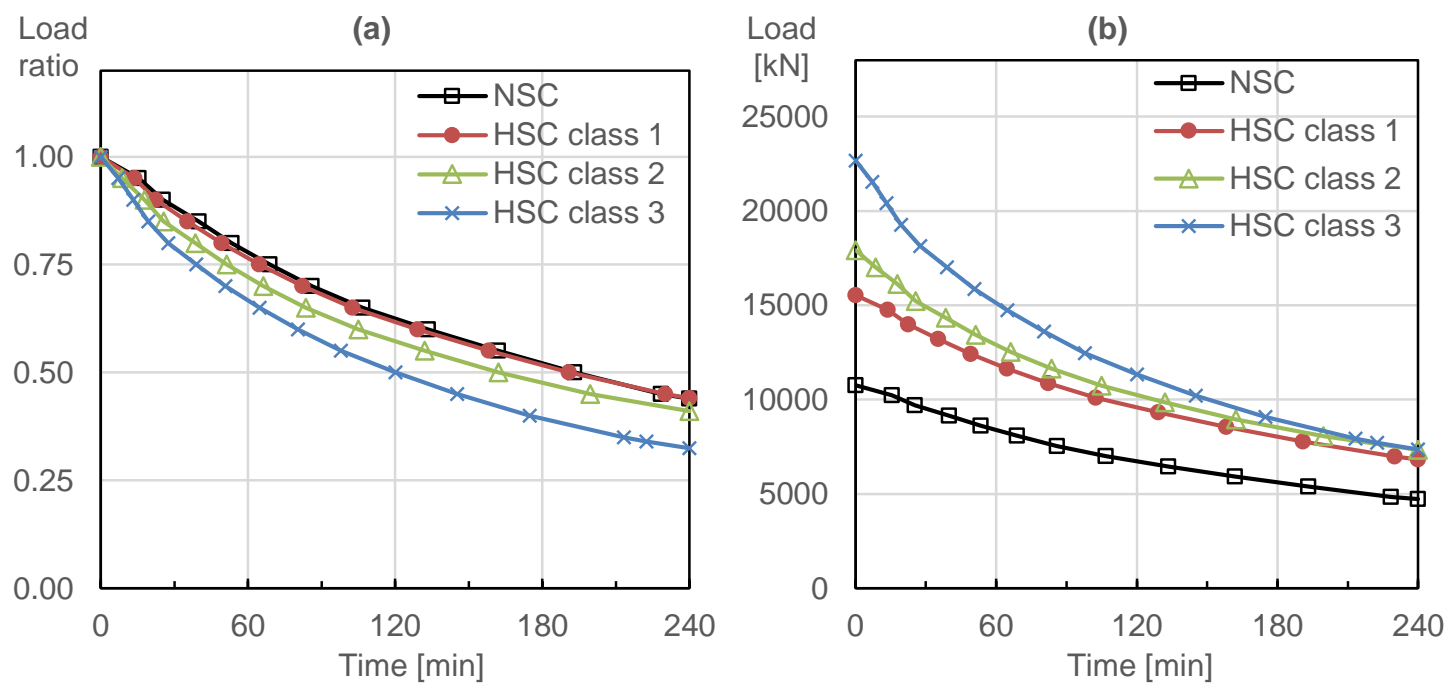

Figure 4. Evolution of load bearing capacity as a function of exposure time to standard ISO fire, in load ratio (a) and in absolute value (b). The columns have the same cross section.

\section{CASE STUDY}

\subsection{Multi-story parking garage}

A reinforced concrete car park structure with 15 stories is analyzed as a case study. Use of HSC can be interesting in parking garages because the layout can be optimized by reducing the size of the columns or increasing the spans.

The parking structure is made of circular columns supporting precast concrete beams and a cast in place concrete slab. The prestressed I-shape beams have a $15 \mathrm{~m}$ span, are separated by $5 \mathrm{~m}$ and are simply supported. The slab thickness is $150 \mathrm{~mm}$. The columns are continuous with an inter-story height of $2.5 \mathrm{~m}$. The design at ambient temperature is made according to Eurocode (EC2, 2004a). The characteristic value of the distributed variable load accounting for the vehicle weight is $2.5 \mathrm{kN} / \mathrm{m}^{2}$, assuming parking areas for light vehicles class $\mathrm{F}$ (EC1, 2002). Besides, snow load typical for Belgium $\left(0.4 \mathrm{kN} / \mathrm{m}^{2}\right.$ for flat roof) is taken into account. A reinforcement ratio of $2 \%$ is assumed for the columns. The columns are designed using a crosssection verification code taking into account the M-N interaction and the second-order effects (based on the nominal curvature). For each adopted strength class (NSC or HSC), the diameter of the circular columns is chosen as the minimum multiple of $50 \mathrm{~mm}$ that provides sufficient member resistance. More detailed information about the design and the implementation of the method used in Matlab can be found in (Peric, 2016).

The obtained section sizes for the columns at floors 1, 6, 11 and 15 are given in Table 3 as a function of the selected concrete strength class (i.e. characteristic cylinder compressive strength at 28 days). The higher gain in column diameter happens for the lower floors, where the columns carry the largest loads. At the first floor, upgrade from C30 to C90 allows for a diameter reduction from $850 \mathrm{~mm}$ to $600 \mathrm{~mm}$, i.e. a reduction of the section area by $50 \%$.

The concrete cover is adapted for each column according to the Eurocode requirements. The cover to the stirrup is taken equal to the diameter of the longitudinal rebar plus $10 \mathrm{~mm}$ (EC2, 2004a). This cover is sufficient to ensure a $60 \mathrm{~min}$ fire resistance to the columns according to the tabulated method of Annex C in Eurocode 2 (EC2, 2004b).

Table 3. Column section sizes for the parking garage.

\begin{tabular}{cccccccc}
\hline$N_{\text {floors }}$ & \multicolumn{7}{c}{$\Phi_{\text {column }}[\mathrm{mm}]$} \\
{$[-]$} & $\mathrm{C} 30$ & $\mathrm{C} 40$ & $\mathrm{C} 50$ & $\mathrm{C} 60$ & $\mathrm{C} 70$ & $\mathrm{C} 80$ & $\mathrm{C} 90$ \\
\hline 15 & 250 & 250 & 250 & 250 & 250 & 250 & 250 \\
11 & 500 & 450 & 450 & 400 & 400 & 400 & 400 \\
6 & 700 & 650 & 600 & 550 & 550 & 550 & 500 \\
1 & 850 & 800 & 750 & 700 & 650 & 650 & 600 \\
\hline
\end{tabular}




\subsection{Numerical analysis in the fire situation}

The concrete columns of the parking garage structure have been analyzed in the fire situation by numerical simulation using the nonlinear finite element software SAFIR. The objective was to assess how the alternative designs made of different concrete strength class, which yield a similar performance as the NSC at ambient temperature, perform in the fire situation. The columns were studied as isolated structural members; the consideration of the structural system behavior was out of the scope of this study. Figure 5 shows the column elevation and support conditions. The buckling length of a column in an intermediate floor is taken as $L_{f i}=0.5 \mathrm{~L}$, with $L$ the inter-story height $(2.5 \mathrm{~m})$, adopting the recommendation for a braced frame given in Eurocode (EC3, 2005). An initial geometric imperfection with a maximum amplitude of $20 \mathrm{~mm}$ is assumed. Figure 5 also shows the temperature distribution in a $700 \mathrm{~mm}$ diameter column after $180 \mathrm{~min}$ of exposure to ISO 834 standard fire.

In the thermo-mechanical calculations by SAFIR, a load was applied on the column which was then subjected to the ISO fire (the load being kept constant) until failure. Successive levels of applied loads were considered for each column to establish the relationship between the applied load level and the fire resistance time. The stress-strain material laws and the reduction of concrete strength with temperature for the different strength classes are adopted from Eurocode. The explicit transient creep model is adopted for concrete (Gernay and Franssen, 2012).
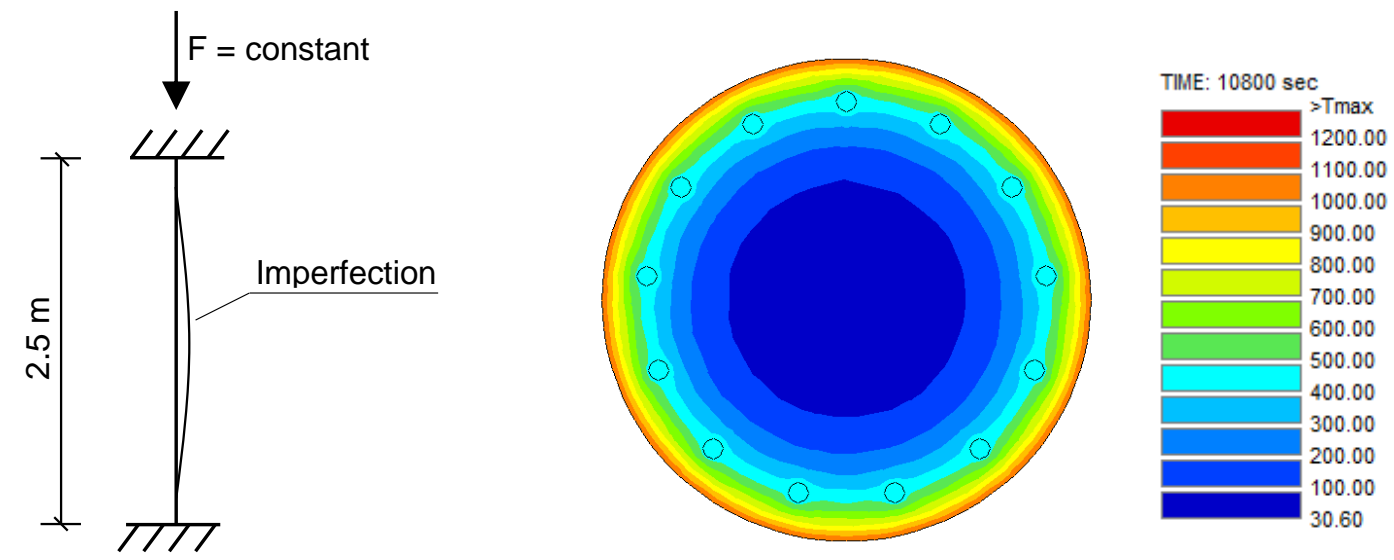

Figure 5. Column elevation and cross section with temperature distribution after 3 hours of ISO fire.

\section{RESULTS}

The results are presented in Figure 6 for the columns on the first floor (hence carrying 15 stories). For a concrete strength class varying from C30 to C90, the outside diameter of the columns varies from $850 \mathrm{~mm}$ to $600 \mathrm{~mm}$, respectively. Figure 6a plots the evolution of the relative load bearing capacity as a function of the exposure time to ISO 834 standard fire. As expected the relative loss is more pronounced for HSC columns than for NSC columns. The column in C90 is the most affected by the fire, as it retains only $64 \%$ of its capacity after 2 hours. In contrast, the column in $\mathrm{C} 30$ retains $86 \%$ of its capacity after 2 hours.

These results show that the replacement of columns in NSC by more slender columns in HSC leads to a reduced fire resistance time. Yet in analyzing the consequences of these results, it is important to consider also the evolution of the load bearing capacity in absolute value (Figure 6b). The initial load corresponds to the capacity of the column in the fire situation at time $0, R_{\mathrm{fi}, \mathrm{d}, 0}$. This initial capacity is approximately identical for the different columns, which confirms that the different designs can be used interchangeably at ambient temperature. The capacity $R_{\mathrm{fi}, \mathrm{d}, 0}$ is significantly higher than $E_{\mathrm{d}}$, which is the design value of the relevant effect of actions from the fundamental combination of loads for the column at ambient temperature. This is due to a combination of factors:

- The column design at ambient temperature is such that $R_{\mathrm{d}} \geq E_{\mathrm{d}}$ (with $R_{\mathrm{d}}$ the design value of the capacity of the column at ambient temperature). Because commercial dimensions 
are used for the steel bar diameter and the column outside diameter, there is a reserve in resistance and $R_{\mathrm{d}}$ generally exceeds $E_{\mathrm{d}}$.

- Besides, $R_{\mathrm{d}}$ includes safety factors on the material strengths, which are not considered in the fire situation. Therefore, $R_{\mathrm{fi}, \mathrm{d}, 0}>R_{\mathrm{d}}$.

- Finally, the support conditions can be assumed as fixed-fixed in the fire situation (EC3, 2005 ), which also increases the capacity $R_{\mathrm{fi}, \mathrm{d}, 0}$ when compared to the situation at ambient temperature.

These factors explain why the curves in Figure $6 \mathrm{~b}$ start significantly higher than the design load at ambient temperature $E_{\mathrm{d}}$. Furthermore, the design load in the fire situation, $E_{\mathrm{fi}, \mathrm{d}}$, is lower than $E_{\mathrm{d}}$. This is due to the fact that, in accidental design situations such as fire, the combination of actions and the safety factors on the loads are less severe than for persistent design situations, due to the small probability of occurrence of the former. The difference between $R_{\mathrm{fi}, \mathrm{d}, 0}$ and $E_{\mathrm{fi}, \mathrm{d}}$ is the initial reserve in resistance.

(a)

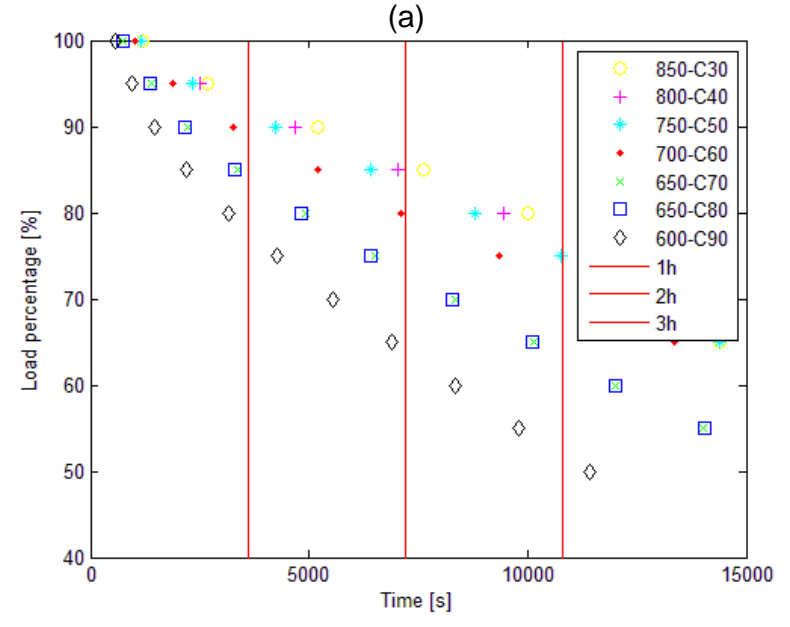

(b)

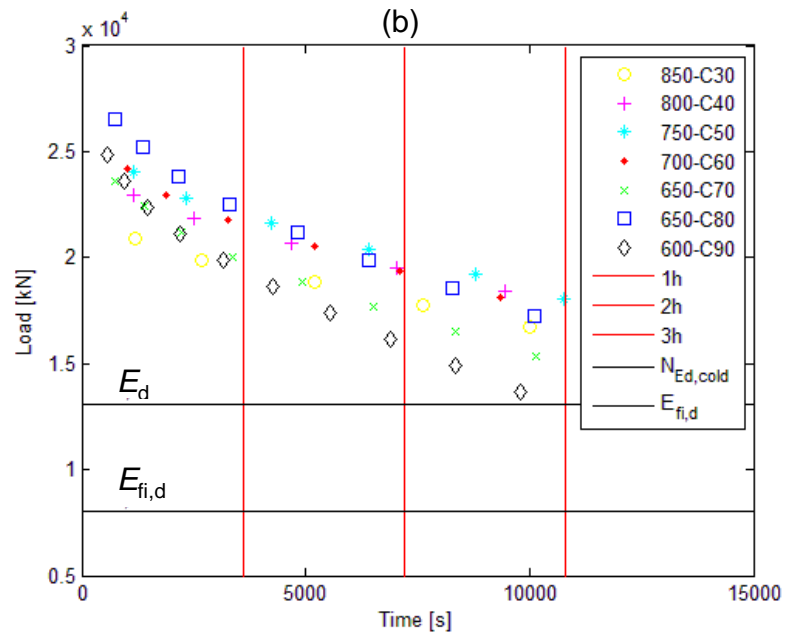

Figure 6. Relationship between applied load on the columns and fire resistance time, in load ratio (a) and absolute value (b) - Floor 1.

(a)

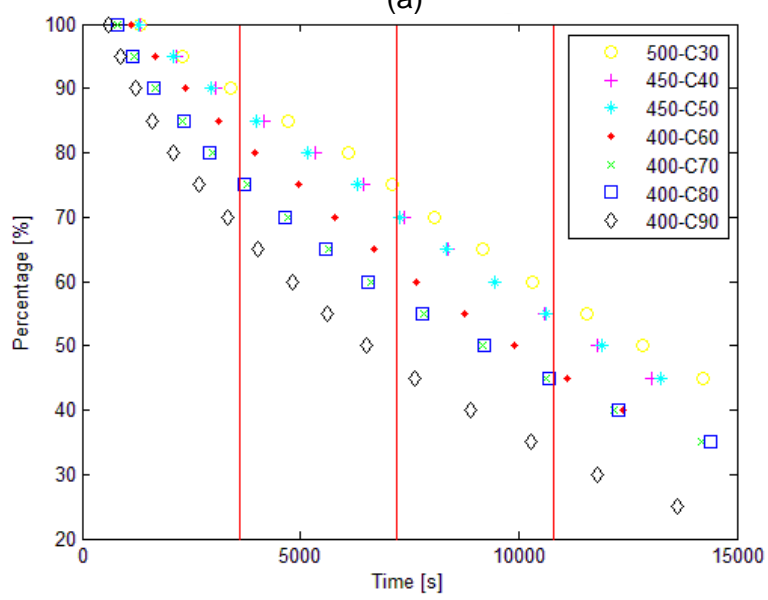

(b)

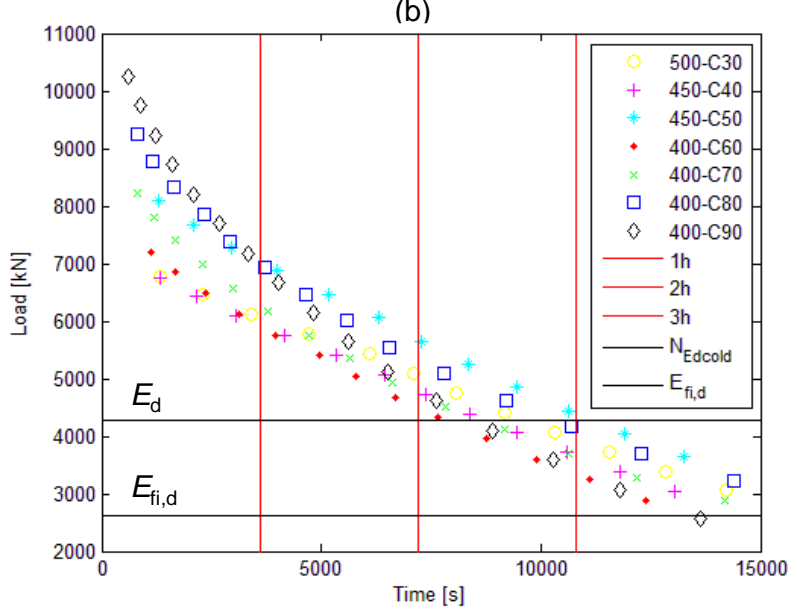

Figure 7. Relationship between applied load on the columns and fire resistance time, in load ratio (a) and absolute value (b) - Floor 11.

Due to the fire action, the capacity of the columns reduces over time, consuming progressively the reserve in resistance. The reduction rate is faster for the columns in higher grades. However, even for the C90 column, the initial reserve in resistance is sufficient to ensure a fire resistance larger than 3 hours. Indeed, the sections are relatively large $(600 \mathrm{~mm}$ for the C90) and, given the low conductivity of concrete, the heat propagation toward the core is 
slow (see Figure 5). As a result, for the relatively stocky columns on the first floor, fire resistance is not likely to be an issue even if C90 strength class is used.

The results for the columns at the eleventh floor are shown in Figure 7. Figure 7a plots the evolution of the relative load bearing capacity as a function of the exposure time to ISO fire. The trend is similar to that of Figure 6a, with a reduction rate in capacity increasing with the concrete strength class. Figure $7 \mathrm{~b}$ plots the evolution of the column capacity in absolute value. The discrepancy in initial capacity between the different columns is more significant than for the first floor, because the section diameters are rounded to multiple of $50 \mathrm{~mm}$ and this limits the possibility for reducing the sections in the smaller sizes. For instance, the C90 and C60 columns both have a diameter of $400 \mathrm{~mm}$, therefore the C90 column has a much higher initial reserve in resistance. Upon heating, the capacity of the $\mathrm{C} 90$ column drops faster than the one of the C60 column, but the two curves cross only after about 150 minutes of fire. Overall, the columns at the eleventh floor also have significant initial reserve in resistance. Their fire resistances are shorter than the ones at the first floor, because the sections are thinner, but still exceed 3 hours under standard ISO fire. As a result, the relative loss in fire performance observed with higher concrete strength class is of no consequence for the studied structure.

\section{CONCLUSION}

This study has investigated the impact on fire resistance of upgrading the concrete strength class in the design of columns. The use of high strength concrete is expected to lead to a decrease in fire resistance due to the conjunction of several factors: a higher rate of strength loss with temperature; a higher propensity to spalling; and in case of smaller sections, a higher rate of temperature increase in the core and an increased slenderness. Based on numerical simulations by finite element method on a case study, the following conclusions can be drawn:

- Columns made of HSC experience a higher rate of reduction of their load bearing capacity when subjected to fire, compared to columns made of NSC. The higher the concrete class, the faster the rate of reduction.

- The effect is much more pronounced when high concrete strength classes are used to replace NSC for carrying a given load with a smaller cross section, as opposed to when the section size is fixed and HSC is used to increase the initial capacity. Indeed, the factors related to the reduction of the section size play a significant role.

- In a 15 story parking structure, use of C90 instead of C30 can save up to 50\% of concrete for the columns at the lower floors, based on design at ambient temperature according to Eurocode.

- The more slender C90 columns will have a shorter fire resistance than the stocky C30 columns that they have replaced; however given the initial reserve of resistance of this type of concrete members the fire resistance remains sufficient. For instance, after 2 hours of ISO fire, the studied $600 \mathrm{~mm}$ diameter column retains $64 \%$ of its initial capacity, which is typically more than the applied load ratio in the fire situation.

- As a conclusion, while it has been confirmed that the fire resistance decreases with an increase in concrete strength class due to the above mentioned factors, this study suggests that this reduction may be of no consequence, the fire resistance of HSC members remaining sufficient at least for configurations similar to the case study. This is notably due to the fact that HSC only allows a significant reduction in section size for very stocky members (Table 3).

It is noted that spalling was not considered in this study. Research has shown that, under certain conditions, spalling is mostly prevented; typically this is the case when the proper amount of polypropylene fibers is added in the mix. However, if the occurrence of spalling is not prevented, this phenomenon will also affect negatively the performance of HSC members and need to be taken into account. The question of how to take it into account in numerical modeling remains yet to be solved. 


\section{REFERENCES}

Bamonte, P. 2008. On the role of second-order effects in HSC columns exposed to fire. in: Proc. 5th Int. Conf. Structures in Fire - SiF'08, Singapore, May 28-30, 440-450.

Cheng, F. P., Kodur, V. K. R., \& Wang, T. C. 2004. Stress-strain curves for high strength concrete at elevated temperatures. Journal of Materials in Civil Engineering, 16(1): 84-90.

EC1. 2002. Eurocode 1: Actions on structures - Part 1-1: General actions - Densities, self-weight, imposed loads for buildings. EN 1991-1-1, Brussels: CEN.

EC2. 2004a. Eurocode 2: Design of concrete structures - Part 1-1: General rules and rules for buildings. EN 1992-1-1, Brussels: CEN.

EC2. 2004b. Eurocode 2: Design of concrete structures - Part 1-2: General rules - Structural fire design. EN 1992-1-2, Brussels: CEN.

EC3. 2005. Eurocode 3: Design of steel structures - Part 1-2: General rules - Structural fire design. EN 1993-1-2, Brussels: CEN.

Franssen, J.M. 2005. SAFIR, A thermal/Structural Program for Modelling Structures under Fire, Eng $J$ A.I.S.C. $42: 143-158$.

Franssen, J.M. \& Gernay, T. 2017. Modeling structures in fire with SAFIR ${ }^{\circledR}$ : Theoretical background and capabilities. Journal of Structural Fire Engineering 8(3).

Gernay, T. \& Franssen, J.M. 2012. A formulation of the Eurocode 2 concrete model at elevated temperature that includes an explicit term for transient creep. Fire Saf. J. 51: 1-9.

Gernay, T. 2012. Effect of Transient Creep Strain Model on the Behavior of Concrete Columns Subjected to Heating and Cooling. Fire Technology 48(2): 313-329.

Gernay, T. 2016. Fire Performance of Columns Made of Normal and High Strength Concrete: A Comparative Analysis. Key Engineering Materials 711: 564-571.

Kodur, V. K. R. 2000. Spalling in high strength concrete exposed to fire: concerns, causes, critical parameters and cures. Advanced Technology in Structural Engineering, pp. 1-9.

Peric, V. 2016. Comparative analysis of the fire performance of columns made of normal and high strength concrete. Master thesis, University of Liege, Belgium.

Phan, L. \& Carino, N. 1998. Review of Mechanical Properties of HSC at Elevated Temperature. J. Mater. Civ. Eng. (ASCE) 10:1(58) 58-65.

Pliya, P., Beaucour, A-L. \& Noumowé, A. 2011. Contribution of cocktail of polypropylene and steel fibres in improving the behaviour of high strength concrete subjected to high temperature. Construction and Building Materials 25: 1926-1934. 